\section{'ONCE MORE UNTO THE BREACH, DEAR FRIENDS, ONCE MORE ...'}

This 'and finally ...' column at the back of Practical Neurology has a mission statement to 'find the best of what you may have missed from the non-neurological journals' and relishes in the last of the journal's declarations of Editorial Policy 'we are allowed to have some fun'. Carphology-as you know-is the delirious picking of imaginary objects and it is intended to allude to the erratic way in which A Fo Ben selects works to review. But to stand still is to go backwards; Snickers was once Marathon, Opal Fruits became Starbust-so what for Carphology? Literature may have an answer. Shakespeare announces the death of Falstaff, stating that Mistress Quickly saw him 'fumble with the sheets and play with flowers and smile upon his fingers' ends' and that she 'knew there was but one way' (Henry V, Act II, Scene III). Charles Marks and colleagues from Cork identify that the Bard is in illustrious company with Flaubert and Tolstoy in identifying floccilation as a preterminal agitation. So perhaps the spin doctors would rebrand Carphology as the Falstaff or Henry V sign. (Although as Henry is already associated, although tenuously with 'the' V-sign via finger mutilation, I sense that Carphology as a term may be safe for now.) OJM 2013;106:93-4.

\section{TO P OR NOT TO P?}

The New England Journal of Medicine (NEJM) has issued recent guidance that asks authors to focus on the scale of effect or strength of association, rather than the maligned $p$ value. Strictly the $p$ value, describes how incompatible the observed data may be with a null hypothesis. Corrections for multiple comparisons, a failure to describe the variability of estimated association (SE) and an inability to disentangle significant group differences need to be carefully considered. NEJM concludes that they will report $\mathrm{p}$ values if they are part of the predetermined method with a rationale for controlling for Type 1 errors, and point estimates and their margins of error should be reported.

N Engl J Med 2019;381(3):285-286.

\section{MIND READING}

Those of us who are paranoid about corporate intrusion in to our private data will have had our worst fears realised with the publication of how high-density electrocorticography can be used to 'decode brain signals' in to text. Why so? Well this groundbreaking science was funded by Facebook. The novel aspect of this project was that it yielded real time results that could facilitate conversation. Considering the challenge, the accuracy rates of produced and perceived utterances were as high as $61 \%$ and $76 \%$, respectively, where chance is $7 \%$ and $20 \%$. Context really matters-but this has the promise to be a tool of some utility where current means of communication are glacially slow or non-existent. Nat Commun. 2019;10(1):3096.

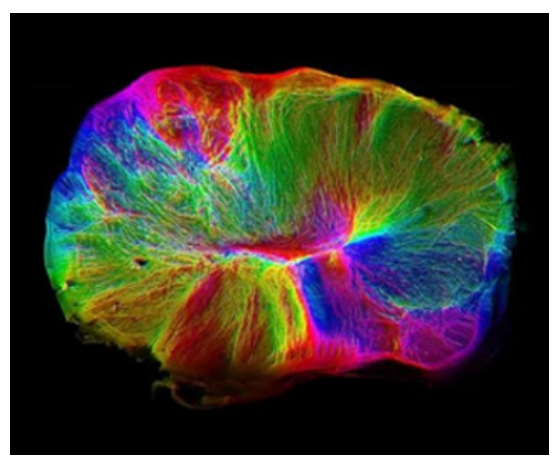

Some scientific advances are breath-taking. A Cambridge team report the organisation of cerebral organoids to create active neuronal networks, and subcortical projecting tracts which can innervate mouse spinal cord explants and evoke contractions of adjacent muscle. Yes, mini-brains in a dish can make muscles twitch. This will be an important method of modelling many human diseases Nat Neurosci. 2019;22(4):669-679.

Funding The authors have not declared a specific grant for this research from any funding agency in the public, commercial or not-for-profit sectors.

Competing interests None declared.

Patient consent for publication Not required.

\section{Provenance and peer}

review Commissioned; internally peer reviewed. 